\title{
Complex craters: Relationship of stratigraphy and rings to impact conditions
}

\author{
John D. O'Keefe and Thomas J. Ahrens \\ Lindhurst Laboratory of Experimental Geophysics, Seismological Laboratory \\ California Institute of Technology, Pasadena
}

\begin{abstract}
One of the key issues associated with the understanding of large scale impacts is how the observable complex crater structural features (e.g., central peaks and pits, flat floors, ring shaped ridges and depressions, stratigraphic modifications, and faults) relate to the impactor's parameters (e.g., radius, velocity, and density) and the nonobservable transient crater measures (e.g., depth of penetration and diameter at maximum penetration). We have numerically modeled large-scale impacts on planets for a range of impactor parameters, gravity and planetary material strengths. From these we found that the collapse of the transient cavity results in the development of a tall, transient central peak that oscillates and drives surface waves that are arrested by the balance between gravitational forces and planetary strength to produce a wide range of the observed surface features. In addition, we found that the underlying stratigraphy is inverted outside of the transient cavity diameter (overturned flap region), but not inside. This change in stratigraphy is observable by remote sensing, drilling, seismic imaging and gravity mapping techniques. We used the above results to develop scaling laws and to make estimates of the impact parameters for the Chicxulub impact and also compared the calculated stratigraphic profile with the internal structure model developed by Hildebrand et. al. [1998], using gravity, seismic and other field data. For a stratigraphy rotation diameter of $90 \mathrm{~km}$, the maximum depth of penetration is $\sim 43 \mathrm{~km}$. The impactor diameter was also calculated. From the scaling relationships we get for a $2.7 \mathrm{~g} / \mathrm{cm}^{3}$ asteroid impacting at $20 \mathrm{~km} / \mathrm{s}$, or a $1.0 \mathrm{~g} / \mathrm{cm}^{3}$ comet impacting at $40 \mathrm{~km} / \mathrm{s}$, an impactor diameter of $\sim 13 \mathrm{~km}$, and for a comet impacting at $60 \mathrm{~km} / \mathrm{s}$, an impactor diameter of $\sim 10 \mathrm{~km}$
\end{abstract}

\section{Introduction and Objectives}

One of the central issues in planetary cratering is how do the measurable crater features relate to the initial impact conditions and the processes that took place during the impact? The measurable crater features include dimensions of central peaks and pits, flat floors, and ring-shaped ridges and depressions. Measurements of seismic and gravity fields and collection and analysis of drill cores potentially provide a description of the lithology and crater structure. The initial impact conditions are characterized by the impactor's radius $a$, velocity $U$, and density $\delta$. Some of the measures of the processes that take place during the impact are the maximum depth of penetration $\left(d_{\mathrm{p}}\right)$, the diameter at maximum penetration $\left(D_{\mathrm{p}}\right)$, and the number and magnitude of centerline oscillations. The depth of penetration in this study is defined by the interface between the projectile and the target at the centerline of impact at a given time. The transient cavity diameter is the diameter of the cavity at the preimpact surface height.

A number of models have been proposed to explain some of the aspects of the formation of complex crater structures. These have ranged from dynamic models [Baldwin, 1949; Murray, 1980; O'Keefe and Ahrens, 1993, 1996; Van Dorn, 1968] to quasi-static models [Leith and McKinnon, 1991; Melosh, 1989]. None of these models quantitatively describe the evolution of the

Copyright 1999 by the American Geophysical Union

Paper number 1998JE000596.

0148-0227/99/1998JE000596\$09.00 crater from the initial penetration to the formation of the final observables or provide a relationship between the transient cavity and the final structure. The importance of the latter is that for large-scale craters the transient cavity dimensions are controlled largely by the impactor parameters ( $a, U$, and $\delta$ ) and the planetary gravitational acceleration $g$ and not by the planetary strength at depth $\left(Y_{s}\right)$. This is fortunate since the strength at depth is difficult to ascertain for planets and other, small, solar system objects.

Baldwin [1949], Van Dorn [1968], and Murray [1980] suggested that the rings around lunar craters formed as the result of the arresting of large fluid-like surface waves driven by the impact event. In the intervening years since these first papers, ring structures have been observed on all solid planets and major satellites in the solar system. Baldwin and Van Dorn based their arguments on ringed craters to the analogous phenomenon of droplet impacts into water and other fluids. These experiments exhibited the formation of a tall transient central peak whose height was an order of magnitude larger than the droplet size and whose amplitude and frequency of oscillations of the peak were interpreted as a driving source of a train of concentric surface waves. While these papers were provocative, they did not provide a quantitative description of the threshold for wave production or a description of the arresting mechanisms for the waves in planetary materials such as solid or fractured rock or ice.

To provide a quantitative basis of understanding, we have numerically modeled large-scale impacts on planets for a range 
Table 1. Scope and Values of Impact and Equation of State Parameters

\begin{tabular}{|c|c|c|c|}
\hline Parameter & Symbol & Range of Values & Units \\
\hline Impact velocity & $U$ & 12 & $\mathrm{~km} / \mathrm{s}$ \\
\hline Planetary gravity & $g$ & 0 to $4.9 \mathrm{e} 5$ & $\mathrm{~cm} / \mathrm{s}^{2}$ \\
\hline Planet density & $\rho$ & 2.7 & $\mathrm{~g} / \mathrm{cm}^{3}$ \\
\hline Impactor density & $\delta$ & 2.7 & $\mathrm{~g} / \mathrm{cm}^{3}$ \\
\hline Impactor radius & $a$ & 500 & $\mathrm{~cm}$ \\
\hline Bulk modulus & $K$ & 7.6e11 & $\mathrm{dyn} / \mathrm{cm}^{2}$ \\
\hline $\begin{array}{l}\text { Intercept of Hugoniot linear shock particle velocity } \\
\text { relationship }\end{array}$ & $S_{\mathrm{o}}$ & $5.25 \mathrm{e} 5$ & $\mathrm{~cm} / \mathrm{s}$ \\
\hline $\begin{array}{l}\text { Slope of linear Hugoniot shock- } \\
\text { particle velocity relationship }\end{array}$ & $S_{1}$ & 1.39 & $\operatorname{deg}$ \\
\hline $\begin{array}{l}\text { Change in shear modulus with } \\
\text { pressure }\end{array}$ & $d \mu / d P$ & 0.0 & - \\
\hline Shear modulus & $\mu$ & 2.33 to $10.0 \mathrm{e} 12$ & $\mathrm{dyn} / \mathrm{cm}^{2}$ \\
\hline Gruneisen coefficient & $\gamma$ & 2.0 & \\
\hline Initial strength at $P=0$ & $Y_{0}$ & 0.0 to $2.4 \mathrm{e} 9$ & $\mathrm{dyn} / \mathrm{cm}^{2}$ \\
\hline Upper limit on strength at $P=\infty$ & $Y_{\mathrm{ul}}$ & 0.0 to $2.4 \mathrm{e} 9$ & $\mathrm{dyn} / \mathrm{cm}^{2}$ \\
\hline Melt temperature & $T_{\mathrm{m}}$ & 1000 & K \\
\hline $\begin{array}{l}\text { Fraction of melt temperature for } \\
\text { strength weakening }\end{array}$ & $\beta$ & 0.8 & - \\
\hline Density lower limit for failure & $\rho_{\ell}$ & 2.2 & $\mathrm{~g} / \mathrm{cm}^{3}$ \\
\hline Density upper limit for failure & $\rho_{u}$ & 2.4 & $\mathrm{~g} / \mathrm{cm}^{3}$ \\
\hline Mohr-Coulomb parameter (internal friction angle) & $d Y / d P$ & $0.0\left(0^{\circ}\right), 1.0\left(45^{\circ}\right)$ & - \\
\hline $\begin{array}{l}\text { Gravitational force/stagnation pressure } \\
\text { (inverse Froude number) }\end{array}$ & $g a / U^{2}$ & 0.0 to $2.0 \mathrm{e}-4$ & - \\
\hline $\begin{array}{l}\text { Planetary strength/stagnation pressure } \\
\text { (inverse Cauchy number) }\end{array}$ & $Y_{\mathrm{s}} / \rho U^{2}$ & 0.0 to $1.0 \mathrm{e}-2$ & 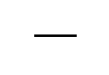 \\
\hline Strength/gravitational force & $Y_{\mathrm{s}} / \rho g d_{\mathrm{p}}$ & 0.0 to 16.7 & - \\
\hline Dimensionless crater depth & $d / a$ & & - \\
\hline Dimensionless crater diameter & $D / a$ & & - \\
\hline Dimensionless time & $U t / a$ & & - \\
\hline
\end{tabular}

Read 4.9e5 as $4.9 \times 10^{5}$. Dash in units column indicates dimensionless.

of impactor parameters and material strengths. These results are an extension of our previous crater calculations [ $O^{\prime}$ Keefe and Ahrens, 1993] out to very late times [O'Keefe and Ahrens, 1996].

\section{Approach and Scope}

We have taken a unified numerical approach [O'Keefe and Ahrens, 1993] and calculated in detail the initial shock wave driven flow fields. We carried out these calculations to include the late stage strength and gravity driven motions that finally end in isostatic equilibrium. The numerical code used was based on the CTH code [McGlaun, 1990], which is an Eulerian material response code with some Lagrangian features. The version of $\mathrm{CTH}$ that we used was modified by us to account for the gravitational forces. The key equation of state parameters used to represent a typical silicate planet and projectile along with the range of material strength parameters are listed in Table 1 . The code explicitly calculates the temperature increase due to both the shock heating and plastic work. This heating results in the degradation of the material strength. To address the material strength, we used a geologic model [Jaeger and Cook, 1979] for both consolidated rock and deep regoliths. This model belongs to the $J_{2}$ class of models, where $J_{2}$ is the second invariant of the stress deviator. This invariant is a function of pressure, temperature and density [Cristescu, 1967]. The yield strength $\left(Y_{\mathrm{S}}\right)$ at any point in the field is given by

$$
Y_{\mathrm{s}}=Y_{\mathrm{d}}+\left(Y_{\mathrm{o}}-Y_{\mathrm{d}}\right) \exp \left[(d Y / d P) P /\left(Y_{\mathrm{o}}-Y_{\mathrm{d}}\right)\right],
$$

where $P$ is the pressure at a given point in the field. Note that when $P=0$, then $Y_{\mathrm{s}}=Y_{\mathrm{o}}$, and when $P$ is very large then $Y_{\mathrm{s}}=Y_{\mathrm{d}}$. The degradation in strength $\left(Y_{\mathrm{d}}\right)$ due to temperature and density variations, when

$$
\frac{T_{\mathrm{m}}-T}{T_{\mathrm{m}}(1-\beta)} \leq 1
$$

and also

$$
\frac{\rho-\rho_{\ell}}{\rho_{u}-\rho_{\ell}} \leq 1
$$

is given by

$$
Y_{\mathrm{d}}=Y_{\mathrm{u} \ell} \frac{T_{\mathrm{m}}-T}{T_{\mathrm{m}}(1-\beta)} \frac{\rho-\rho_{\ell}}{\rho_{\mathrm{u}}-\rho_{\ell}}
$$

and when either

$$
\frac{T_{\mathrm{m}}-T}{T_{\mathrm{m}}(1-\beta)}>1
$$


or

$$
\frac{\rho-\rho_{\ell}}{\rho_{u}-\rho_{\ell}}>1
$$

then

$$
Y_{\mathrm{d}}=0
$$

where $Y_{\mathrm{o}}$ is the strength at zero pressure at a given reference temperature, $Y_{\mathrm{u} \ell}$ is the strength at infinite depth in the target, $d Y / d P$ is the rate of increase of the yield strength with confining pressure, and $\rho$ and $T$ are the local density and temperature of the target. Note that $d Y / d P$ is related to the coefficient of internal friction by $d Y / d P=\tan \theta$ where $\theta$ is the angle of internal friction. Consolidated rock surfaces were modeled assuming $d Y / d P=0$. This is the same assumption used in O'Keefe and Ahrens [1993] and is equivalent to a Von Mises strength model. Above, $\rho_{u}$ is the upper limit of density for which the strength is not changed by density degradation term in equation (2), $T_{\mathrm{m}}$ is the melting temperature, $\beta$ is the fraction of the melt temperature at which the strength starts to degrade, and $\rho_{\ell}$ is the density at which the material fails in hydrostatic tension and the strength is zero. In this model, for temperatures greater than $\beta T_{m}$, the strength linearly approaches zero with increasing temperature (equation (2), temperature degradation term). In addition, if the density is decreased to values below $\rho_{\ell}$, the strength is also reduced to zero (equation (2), density degradation term). This strength model allowed us to bound the responses expected from planets with deep regoliths to highly consolidated surfaces and to include the effects of shock and plastic work heating. In summary, this model addresses strength weakening due to shock heating, plastic work, temperature softening, and extensional failure at densities less than normal. However, there are other effects that degrade the strength that were not part of this study and are active areas of investigation; these include compressive fracturing, comminution [O'Keefe and Ahrens, 1999], frictional heating, and acoustic fluidization [Melosh and Ivanov, 1999].

We varied the surface gravity and material strength so as to encompass a range of impact conditions and crater morphologies from simple to complex [O'Keefe and Ahrens, 1993, 1996]. To put these results in a unified context and to develop scaling laws for key crater measures, we nondimensionalized the results using the formalism of Holsapple and Schmidt [1987]. These dimensionless parameters are the inverse Froude number, $g a / U^{2}$ (gravitational stress/dynamic pressure force), and inverse Cauchy number, $Y_{\mathrm{s}} / \rho U^{2}$ (strength /dynamic pressure force). These are commonly referred to as gravity and strength scaling parameters.
As in our previous study, we have restricted the impacts to silicate upon silicate and the impact velocity to $12 \mathrm{~km} / \mathrm{s}$, such that significant amounts of vaporization would not occur. The reason for this is to easily follow the interface between the impactor and the planetary surface so as to establish the relevant scaling laws. The vaporization has an insignificant effect on the evolution of the crater morphology for nonvolatile terrestrial planets and objects. This lower impact velocity does reduce the amount of shock heating and thermal strength reduction. However, this is not significant for ranges of strength for most planetary surfaces except for those that are near their melting points or for microimpacts where the apparent strength is large. The ranges of variation of the above parameters are given in Table 1 . The gravity scaling parameter $\left(\mathrm{ga} / \mathrm{U}^{2}\right)$ ranges from 0.0 to $2.0 \times 10^{-4}$ and the strength scaling parameter $\left(Y_{\mathrm{s}} / \rho U^{2}\right)$ ranges from 0.0 to $1.0 \times 10^{-2}$. The scaling parameter that determines the final crater morphology is $Y_{\mathrm{s}} / \mathrm{pgd}$. This parameter is the planetary material strength normalized by the overburden pressure at the maximum depth of penetration under zero-strength conditions. This is a measure of the degree to which a planet can support a feature of a given characteristic height relative to the maximum depth of penetration. If this parameter is $>0.15\left(Y_{s} / \rho g d_{p}>0.15\right)$, then the crater is simple, and conversely, if it is $<0.15\left(Y_{\mathrm{s}} / \rho g d_{\mathrm{p}}<0.15\right)$, then the crater is complex. Note that for large-scale craters the maximum depth of penetration is governed by gravitational forces and not the strength [O'Keefe and Ahrens, 1993]. The maximum depth of penetration for large-scale craters is given by

$$
d_{\mathrm{p}}=0.96 a(\mathrm{p} / \delta)^{-0.26}\left(\mathrm{ga} / U^{2}\right)^{-0} 22
$$

(see Table 2 and scaling law 1). We did not vary the density of the impactor in these calculations, but we used the scaling relationship developed by Holsapple and Schmidt [1987] for assessing impactor density variations.

In order to delineate the effect of the crater motions on the deformation of the planet's stratigraphy we have placed massless tracer particles at various depths. These tracers were used to determine (1) the deformation in the stratigraphy and (2) temporal history of motions of material particles placed at various depths. The temporal histories were used to determine the depths of excavation and mixing. The stratigraphic deformations and the particle histories are given on the right-hand and lefthand sides, respectively, in all of the crater plots. The arrowhead on the temporal histories of the particle motions depicts the position at the dimensionless time given in the figure caption and

\begin{tabular}{|c|c|c|c|}
\hline Definition & Scaling Law & $\begin{array}{l}\text { Standard Deviation } \\
\text { of Fits to Data in } \\
\text { Figure 1a } \\
\end{array}$ & Scaling Law \\
\hline $\begin{array}{l}\text { Depth of penetration } \\
\text { ( gravity driven- zero } \\
\text { strength) }\end{array}$ & $d_{\mathrm{p}} / a=0.96(\rho / \delta)^{-0.26}\left(g a / U^{2}\right)^{-0.22}$ & 0.08 & 1 \\
\hline $\begin{array}{l}\text { Diameter at maximum depth } \\
\text { of penetration }\end{array}$ & $D_{\mathrm{p}} / a=1.82(\mathrm{\rho} / \delta)^{-0.26}\left(g a / U^{2}\right)^{-022}$ & 0.08 & 2 \\
\hline $\begin{array}{l}\text { Diameter where stratigraphy } \\
\text { is rotated by } \sim 90^{\circ}\end{array}$ & $D_{\mathrm{st}}=1.12 D_{\mathrm{p}}$ & 0.05 & 3 \\
\hline Depth of excavation & $d_{\mathrm{ex}}=0.1 D_{\mathrm{p}}$ & 0.01 & 4 \\
\hline Maximum stratigraphic uplift & $\Delta Y_{s l}=0.25 D_{p}$ & 0.01 & 5 \\
\hline $\begin{array}{l}\text { Diameter / maximum depth of } \\
\text { penetration }\end{array}$ & $D_{\mathrm{p}} / d_{\mathrm{p}}=1.9$ & 0.08 & 6 \\
\hline Impactor diameter $(2 a)$ & $2 a=0.8(\rho / \delta)^{1 / 3} D_{\mathrm{st}}\left(g D_{\mathrm{st}} / U^{2}\right)^{056}$ & 0.08 & 7 \\
\hline
\end{tabular}
the direction of the arrowhead gives the direction of the motion.

Table 2. Summary of Scaling Laws for the Gravity-Driven Complex-Crater Regime 


\section{Results}

The evolution of a planetary hypervelocity impact crater can be described in terms of three successive scaling regimes [Holsapple and Schmidt, 1987; O'Keefe and Ahrens, 1993]. These scaling regimes are similar to those discussed by Melosh [1989], however these are quantified and delimited by the underlying cratering mechanics scaling laws. The first is the penetration regime. This is characterized by the transfer of the kinetic energy of the projectile to the planetary surface. The projectile deforms and lines the cavity of the crater during this time. The material strength properties and the gravitational force are not important, and the depth of penetration grows linearly with time during this regime. The second regime is the inertial regime in which the hemispherical shape of the transient cavity remains invariant; however, the absolute size of the cavity increases with time at rate less than linear (depth is $\sim \mathrm{t}^{0.37}$ ) [Holsapple and Schmidt, 1987; O'Keefe and Ahrens, 1993]. Also in this regime, the material strength and gravitational acceleration are not important. However, either the material strength or the gravitational acceleration determines the termination of this regime and whether or not the third oscillation regime occurs. When $Y_{\mathrm{s}} / \mathrm{\rho} g d_{\mathrm{p}}>0.15$, cratering ends in this regime as planetary strength terminates the growth of the crater. The final crater has a simple bowl shape. In contrast, when $Y \mathrm{~s} / \rho g d_{\mathrm{p}}<0.15$, the gravitational force terminates the growth of the inertial regime and the third, oscillation, regime begins. While, in this case, the inertial regime is terminated by the gravitational force, the final phase of the dynamic evolution of the crater is ended when there is balance between strength and the gravitational force. The transition between simple and complex craters was found to be fairly abrupt and occurs for $Y_{\mathrm{s}} / \rho g d_{\mathrm{p}} \sim 0.15$. Since we did not model all of the weakening mechanisms such as fracturing and communition, we expect that the value of the strength at depth at this transition boundary will increase. The calculations of $O$ 'Keefe and Ahrens [1999] of impact damage and faulting found that the boundary did move out by at least one order of magnitude, however the full extent was not delineated.

The penetration and inertial regimes are discussed in detail by O'Keefe and Ahrens [1993]; here we will show the evolution from simple to complex, but we will concentrate on the final oscillation regime and its implications. At the end of the oscillation regime, when the motion has ceased, thermal gradients in the target that are induced by shock, plastic work heating, and stratigraphic uplifting can result in very late time crater subsidence, fracturing, and faulting [Bratt et al., 1985]. These effects are not addressed here.

Examples of simple bowl-shaped, simple flat-floored, complex craters and craters in fluids are shown in Figures 1-6. The time is nondimensionalized by dividing by $a / U$.

\subsection{Simple Bowl-Shaped Craters}

An example of a simple bowl-shaped crater is shown in Figure 1. This case is for $Y_{\mathrm{s}} / \mathrm{pg} d_{\mathrm{p}}=2.87$ and has the same crater shape as cases we have run for $Y_{\mathrm{s}} / \rho g d_{\mathrm{p}}$ up to 17 . This bounds most cases of planetary interest in the strength regime. In the case of simple bowl-shaped craters, cratering ends as the flow enters the inertial regime. The inertial regime is terminated by the strength of the material surrounding the crater, and the final crater shape is reached near the time of maximum penetration except for the
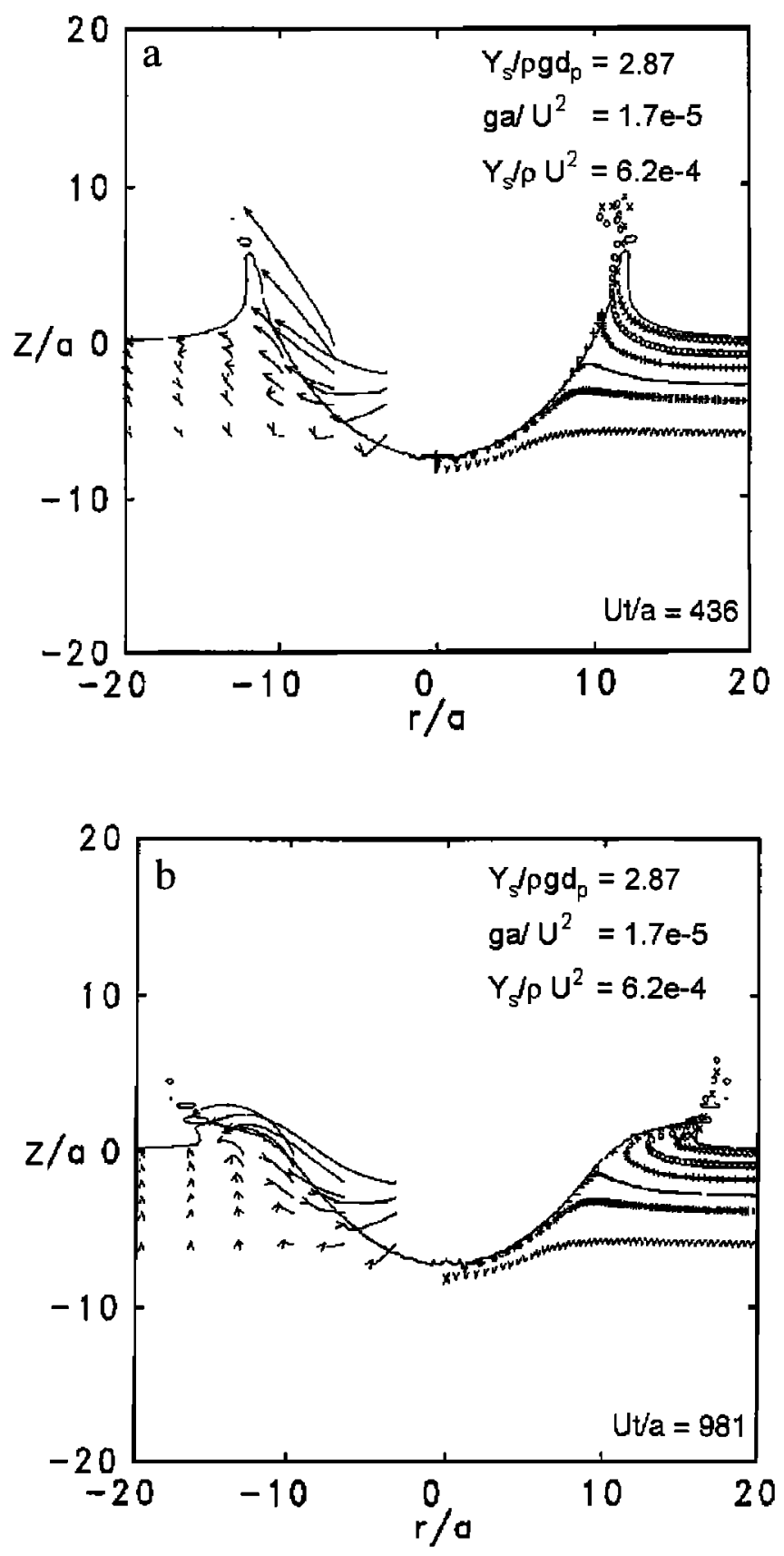

Figure 1. Simple bowl-shaped crater formation: (a) Crater morphology at time of maximum penetration, $U t / a=436$. (b) Crater morphology near end of folding over transient crater lip, $U t / a=981 . Z / a$ is height dimension normalized by impactor radius, and $r / a$ is radial dimension normalized by impactor radius. Stratigraphy is delineated by massless tracer particles placed at various horizontal depths. Different symbols are used to distinguish an array of massless particles placed at various initial depths.

folding over of the crater lip. The time history of the depth of penetration is given in Figure 6, and shows the termination of the growth. The crater shape at the time of maximum penetration is shown in Figure 1a. The stratigraphy along the centerline is compressed and driven downward. The preimpact ordering of 

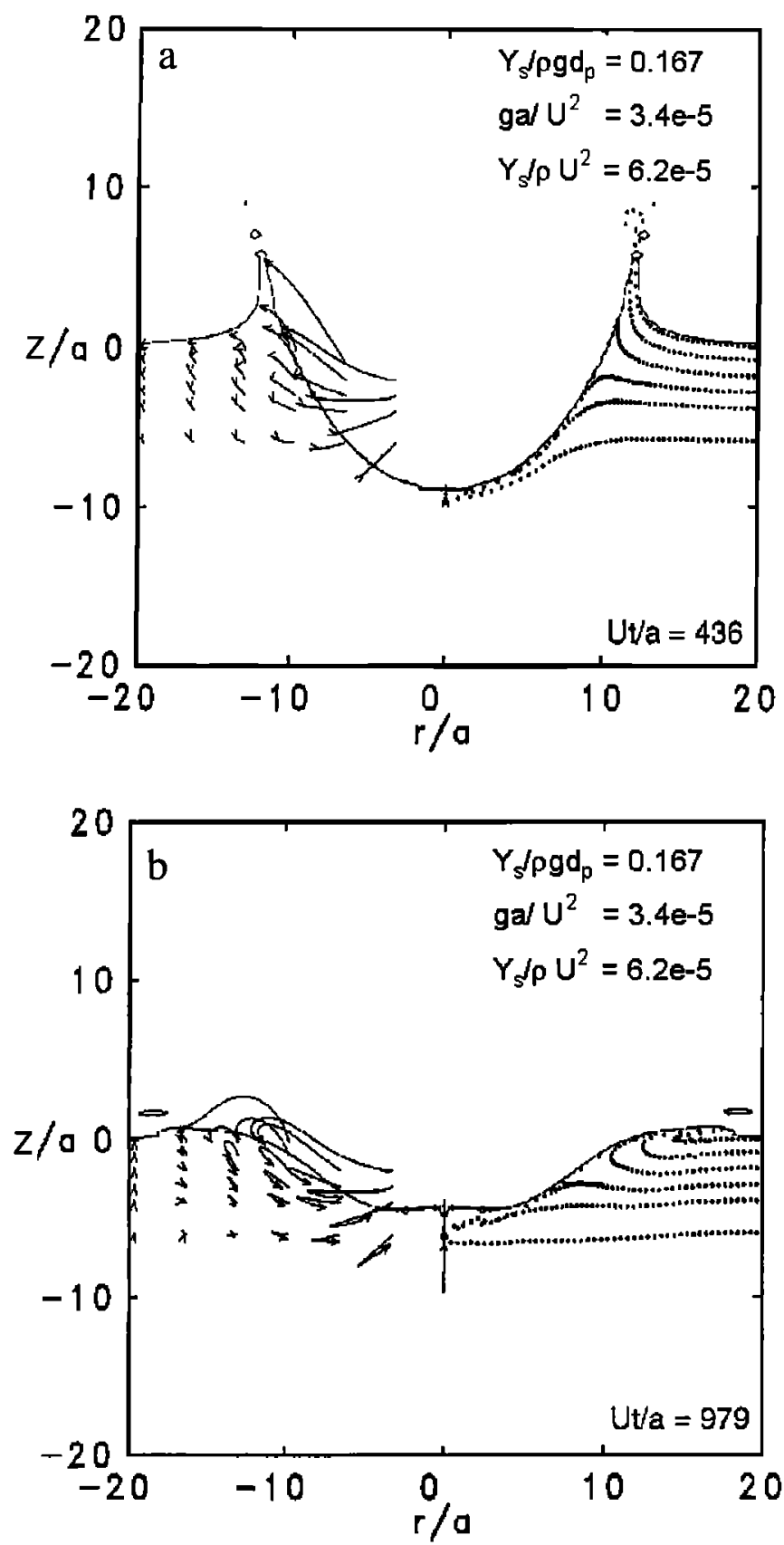

Figure 2. Flat-floored crater formation. (a) Crater morphology at the time of maximum penetration, $U t / a=436$. (b) Final crater morphology, $U t / a=979 . Z / a$ and $r / a$ are defined in Figure 1 caption.

the stratigraphy is preserved everywhere at the time of maximum penetration except for a narrow region near the centerline of the cavity where there is some mixing. The compression of the stratigraphy and the position histories of the tracer particles are shown in Figure 1. In the final stage (Figure 1b) the crater lip, which was formed during the evolution of the transient cavity, has folded over and results in an inverted stratigraphy away from the crater wall. The change in the stratigraphy at the crater wall from dipping upward to dipping downward with increasing radius is a measure of the maximum depth of excavation. The dip of an initially horizontal reference surface within the target rocks with increasing radial distance implies that the material was ejected out of the transient cavity, and conversely, dipping downward implies that the material was driven downward.

\subsection{Flat-Floored Craters}

Simple, flat-floored craters occur in the transition regime between simple and complex craters. An example of a simple flat-floored crater with a slight central mound is shown in Figure $2 \mathrm{~b},\left(Y_{s} / \rho g d_{\mathrm{p}}=0.167\right)$. In this case, the downward growth of the crater in the inertial regime is terminated primarily by the gravitational force. The transient cavity that is formed rebounds only slightly until the gravitational restoring forces are balanced by the planet's strength. The primary effect of the gravity force is to flatten the crater. The time evolution of the depth of penetration and the rebounding is shown in Figure 7. The postimpact stratigraphy in this case is similar to the simple bowl-
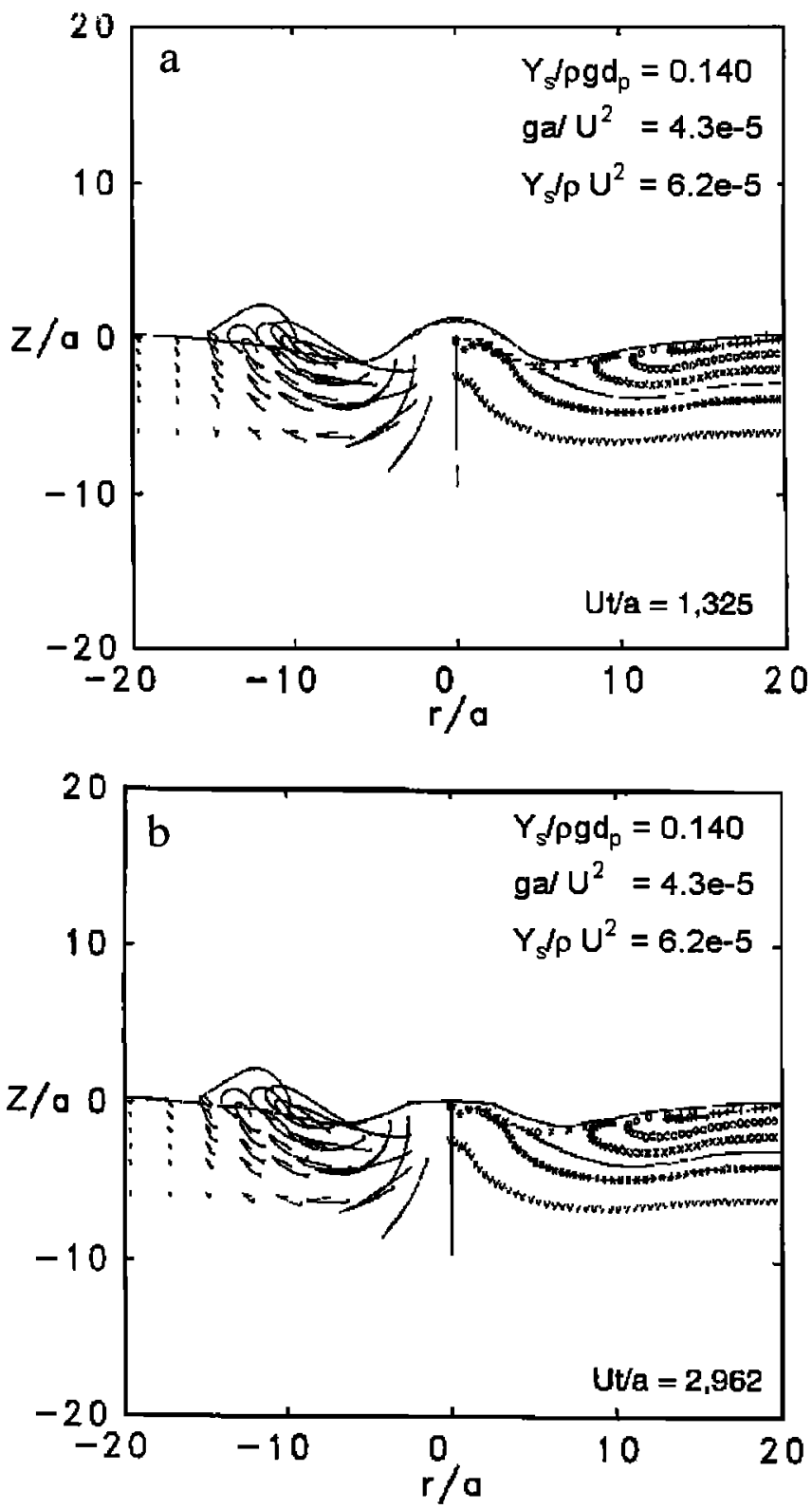

Figure 3. Complex crater formation. (a) Crater morphology at the time of maximum centerline peak oscillation, $U t / a=1325$. (b) Final crater morphology, $U t / a=2952 . Z / a$ and $r / a$ are defined in Figure 1 caption. 

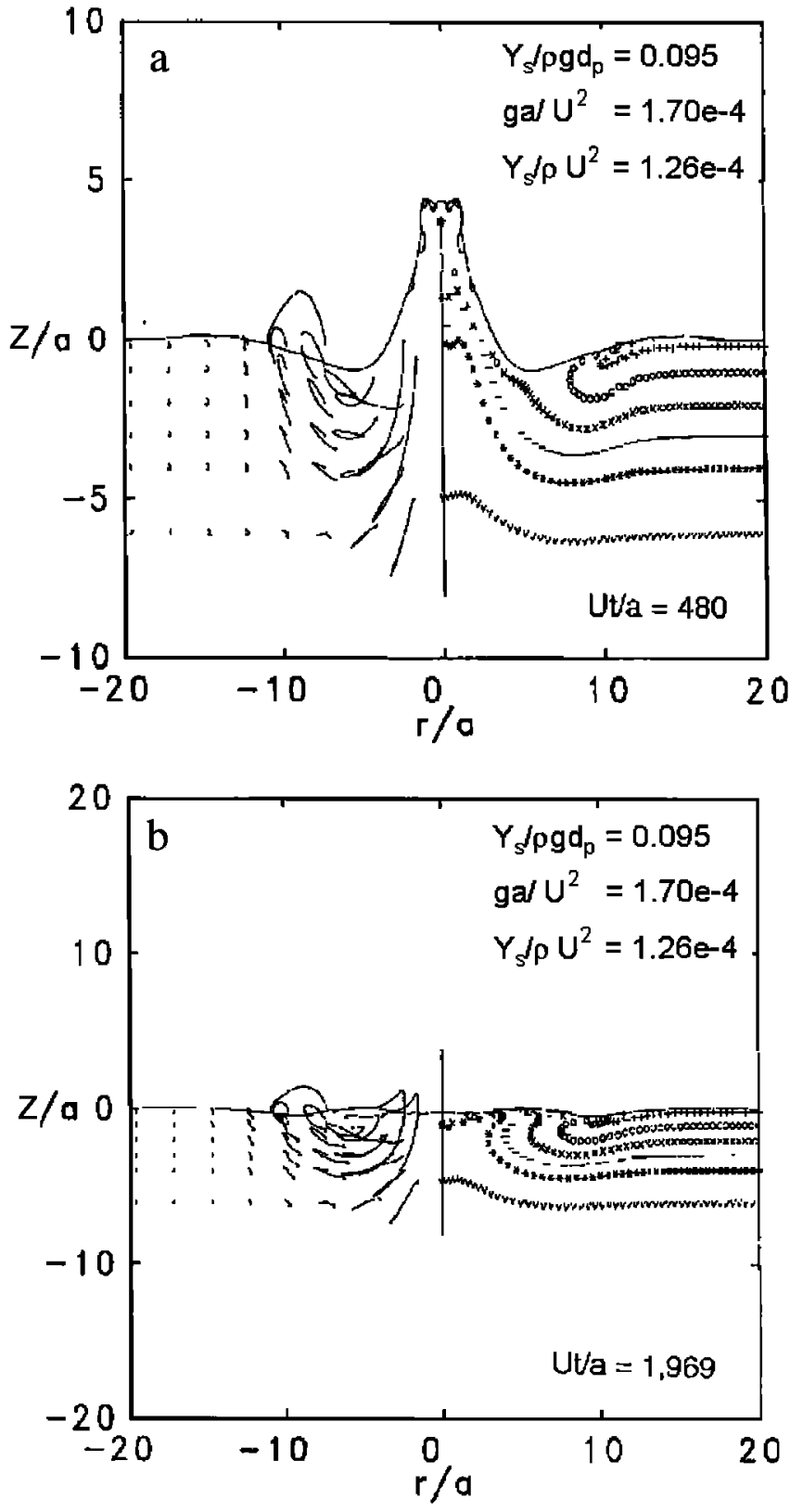

Figure 4. Complex crater formation. (a) Crater morphology at the time of maximum centerline peak oscillation, $U t / a=480$. (b) Final crater morphology, $U t / a=1969 . Z / a$ and $r / a$ are defined in Figure 1 caption.

shaped crater but with less compression in the centerline region. The compression of the stratigraphy and the position histories of the tracer particles showing the rebounding of the central region are given in Figure $2 \mathrm{~b}$. Note that the crater depth is $30 \%$ less than the strength-dominated example in Figure $1 \mathrm{~b}$.

\subsection{Complex Craters}

Complex craters occur when there are significant centerline oscillations of the target rock. We define "significant" as meaning that the maximum centerline oscillation height must be above the preimpact planetary surface. Examples of craters with increasing centerline oscillation heights and frequency are given in Figures 3-6. The centerline motion histories are given in Figure 7. Figure 3 shows the case where there is a single oscillation that relaxes to a central mound $\left(Y_{\mathrm{s}} / \rho g d_{\mathrm{p}}=0.14\right)$. Figure 4 shows the case where there is a single large oscillation that collapses to give a small second transient cavity and a final ringed structure $\left(Y_{\mathrm{s}} / \rho g d_{\mathrm{p}}=0.094\right)$. Figure 5 shows the case where there are two large centerline oscillations $\left(Y_{\mathrm{s}} / \rho g d_{\mathrm{p}}=0.047\right)$. Figure 6 shows the case of an impact into a fluid, where there are three significant centerline oscillations $\left(Y_{s} / \rho g d_{\mathrm{p}}=0.0\right)$. We will discuss the latter two cases in more detail below.

The evolution of a complex crater where there are two large centerline oscillations $\left(Y_{\mathrm{s}} / \rho g d_{\mathrm{p}}=0.047\right)$ is shown in Figure 5 at several dimensionless times. The crater shape at the time of maximum depth of penetration is shown in Figure 5a. This transient cavity collapses and induces an upward flow of the cavity floor to produce an oscillating centerline peak. In Figure $5 \mathrm{~b}$ a centerline peak has formed and is at its first maximum height. The crater lip, which also formed during the development of the transient crater (Figure 5a), is folded over by this time and has a stratigraphy that is rotated at positions away from the wall of the transient cavity. The stratigraphy in the region near the transient cavity maximum diameter is rotated by over $90^{\circ}$ (see Figure $5 \mathrm{~b}$ ). The first peak collapses and forms a second transient cavity, which is shallower than the first (see Figure 5c).

The stratigraphy at and near the centerline is mixed by the motions of the centerline oscillations, whereas the stratigraphy outside the transient cavity region has nearly a $90^{\circ}$ rotation. The mixed region has its greatest vertical extent at the centerline and diminishes outward. The inner ring region is delineated in Figure 5f. This inner ring does not form in fluids (see Figure 6). The ring forms because the material near the centerline of impact is weaker than the material away from the centerline. The material near the centerline is weaker in these calculations because of greater shock heating, plastic work, and extensional failure. While we do not model fracturing and comminution effects, these would also result in the material at the centerline being weakened, and the mechanisms for ring formation will be similar. The effect of increasing the impact velocity would be to increase the relative amount of thermal weakening due to shock heating. The weakened material, which during the development of the transient crater lined the transient cavity, was transported and concentrated toward the centerline by the inward collapse of the transient cavity. This mapping from a hemispherical shell structure of weakened material into a centerline cylinder produces the inner ring. In fluids, there is, of course, no strength and thus no lateral variation in residual strength to produce the inner ring.

Figure 5. Complex crater formation. (a) Crater morpho'ogy at time of maximum penetration, Ut/a=188. (b) Crater morphology at time when first central oscillation reaches its maximum height, $U t / a=725$. (c) Transient crater morphology resulting from collapse of first central peak, $U t / a=1111$. (d) Crater morphology at end of oscillation phase, $U t / a=1949$. $Z / a$ and $r / a$ are defined in Figure 2 caption radius. (e and f) Vertical expansions of Figures $5 \mathrm{~b}$ and $5 \mathrm{~d}$. 

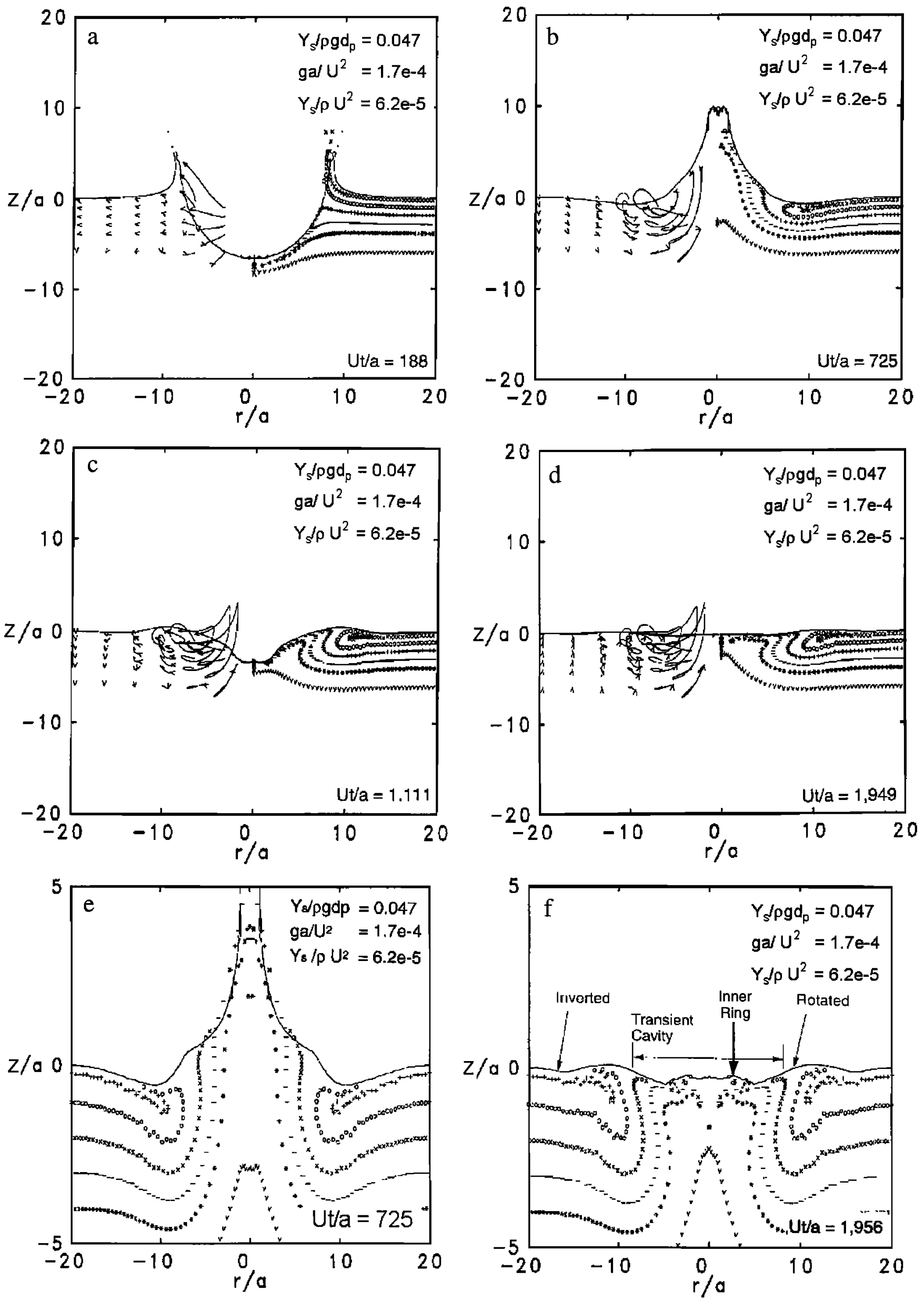

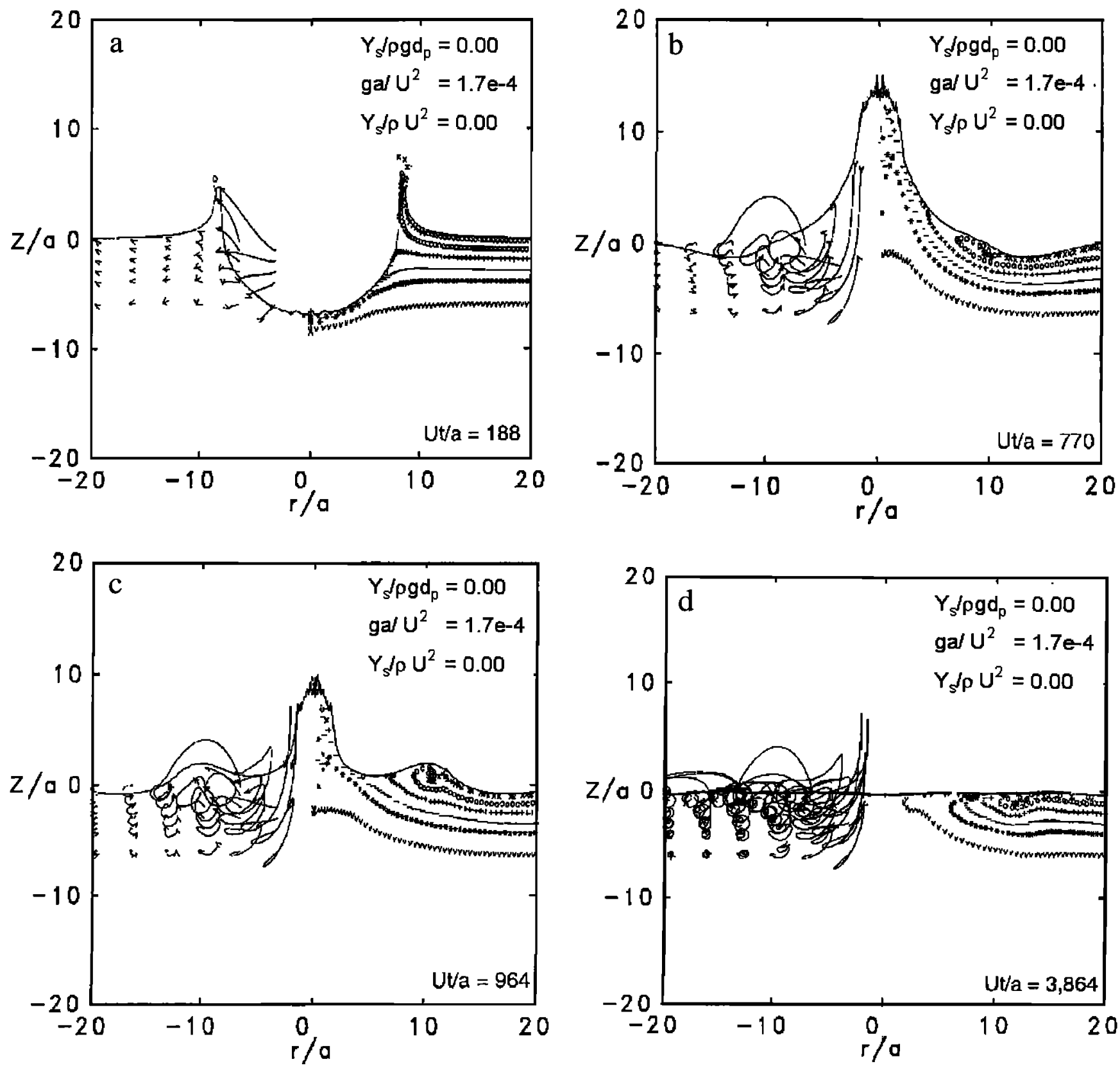

Figure 6. Fluid impact crater formation. (a) Crater morphology at time of maximum penetration, $U t / a=188$. (b) Crater morphology at time of first oscillation reaches maximum height, $U t / a=770$. (c) Collapse of first peak, Ut/a $=964$. (d) Stratigraphy and final surface, $U t / a=3864$. Z $/ a$ and $r / a$ are defined in Figure 1 caption.

Continuing with the evolution of the crater in Figure 5, the second transient cavity rebounds (Figure $5 \mathrm{c}$ ) and produces a small narrow second centerline peak; this decays to give a central structure. In the case shown, there is a small centerline peak ring and an inner ring (Figure 5f). The peak ring has a mixed stratigraphy as opposed to what we have called the inner ring, which has a rotated stratigraphy. The first oscillation peak during its collapse and the final crater form are shown in Figures 5e and $5 f$ with an expanded vertical scale to better illustrate the deformation of the initial stratigraphy. The associated transient crater diameter at the time of maximum penetration is 16 units $(D / a)$. The peak of the inner ring has a diameter of 14.9 units.

The time history of the kinetic energy in the flow field and the centerline displacement is given in Figure 8. It shows minima in kinetic energy at times of maximum upward displacement. In addition it shows that at the time of maximum penetration (downward displacement), there is still a significant amount of kinetic energy in the flow field that can contribute to the collapse of the transient cavity. This contribution due to kinetic energy in the flow field was not considered in the quasistatic approaches to crater collapse [Leith and McKinnon, 1991; Melosh, 1989].

The shape of the final crater surface is a function of the variation of the planet's strength with depth. In addition to the above case where the strength was a function of the overburden pressure and increased linearly with depth up to the maximum strength (deep regolith), we examined the case where there was no variation in strength with depth (consolidated surface). For identical impactor conditions $(a, U, \delta)$ the deep regolith surface 


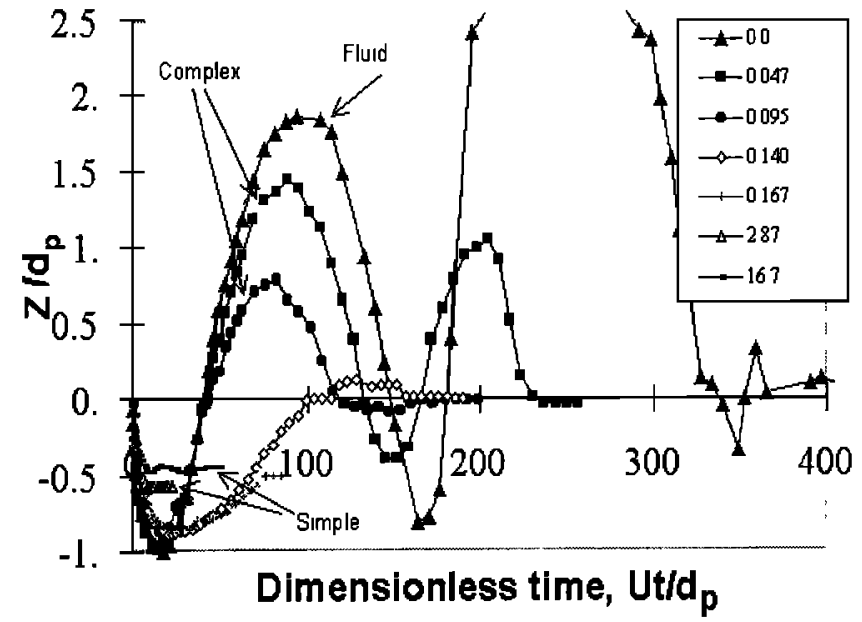

Figure 7. Displacement histories of the impactor-planet interface. Time is normalized by $U / d_{\mathrm{p}}$, and displacements $Y$ of the impactor-planet interfaces are normalized by $d_{\mathrm{p}}$. Increasing planet's strength reduces relative depth of penetration and number of oscillations. Cases shown assumed a geologic strength model with $d Y / d P=1.0$ and $Y_{0}=0.0$.

resulted in a shallow peak ring, whereas the consolidated surace resulted in a narrower but taller central peak (see Figure 9).

\subsection{Excavation Cavity}

The zone of excavated material or the excavation cavity was determined from the tracer particle trajectories. The excavation cavity is defined as that zone of material that is ejected ballistically from the crater. This is shown in Figure 10. In the case of complex craters the transient cavity starts rebounding prior to the completion of excavation of material. The maximum radial extent of the zone of excavation is greater than the transient cavity radius at the time of maximum penetration. The excavation cavity has a maximum depth normalized by the transient cavity diameter at the time of maximum penetration $\left(d_{\mathrm{ex}} / D_{\mathrm{p}}\right)=0.1$ for the geologic model with $d Y / d P=1.0$ and $Y_{0}=0$. The shape would vary with the magnitude of $d Y / d P$. The uncertainty in determining this depth is largely determined by the horizontal spacing of the tracer particles. The depth is zero at the

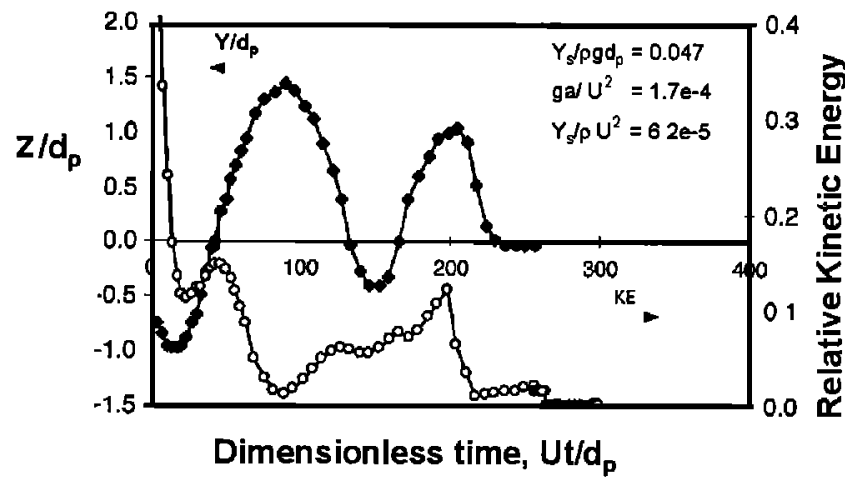

Figure 8. Time history of centerline interface height between impactor and planetary surface normalized by $d_{\mathrm{p}}$ and time history of kinetic energy in the flow field normalized by impactor energy. Time is normalized by $U / d_{\mathrm{p}}$, where $d_{\mathrm{p}}$ is the maximum depth of penetration for zero strength and is given in Table 2 , scaling law 1 . Height of the centerline is also normalized by $d_{\mathrm{p}}$.

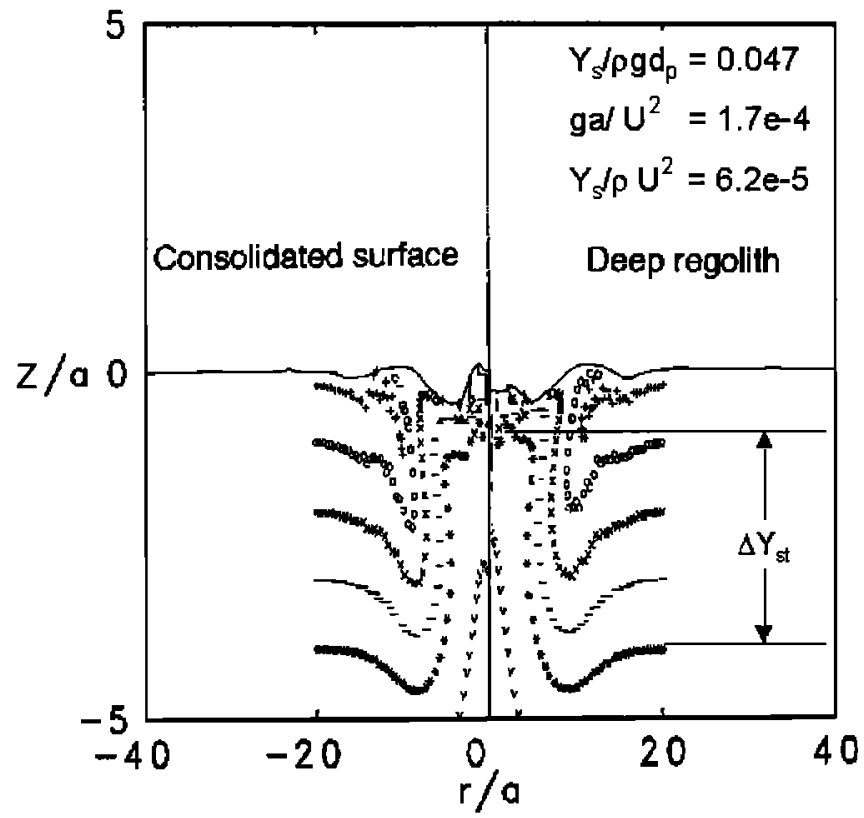

Figure 9. Final crater morphology in rock $(d Y / d P=0.0)$ versus regolith $(d Y / d P=1.0)$ planetary material. Formation of a central peak in rock (left) versus formation of a peak ring in a regolith planetary material (right) for same impactor parameters. Z/a and $r / a$ are defined in Figure 1 caption. An example of the magnitude of the stratigraphic uplift, $\Delta Y_{\mathrm{st}}$, is shown.

centerline and also at the distance corresponding to the transient cavity radius. The material from this zone is transported ballistically to become the material in the overturned flap. This calculated, relatively shallow depth of excavation agrees with summaries of the terrestrial measurements [O'Keefe and Ahrens, 1993].

\subsection{Crater Uplift}

The collapse of the transient cavity results in a series of vertical oscillations of the target rock near the centerline of impact. Because of ejection of material from the transient crater and outward displacement of material, the material near the centerline is permanently displaced in the upward direction. The tracer particles showing these motions are given in Figure 10. From these calculations we determined that the maximum stratigraphic displacement $\left(\Delta Y_{\mathrm{st}}\right)$ normalized by the transient cavity diameter $\left(\Delta Y_{\mathrm{sl}} / D_{\mathrm{p}}=0.25\right)$. The results are plotted in Figure 1a. The stratigraphic upward displacement also carries with it the preimpact thermal distribution along with the temperature distribution due to impact-induced shock and plastic work heating. This uplifting results in a thermal disequilibrium that could drive very late stage thermoelastic crater modifications. These modifications include subsidence due to cooling and concentric fracturing due to thermal contractions [Bratt et al., 1985; O'Keefe and Ahrens, 1998].

Estimates of the amount of stratigraphic uplift in craters on the Earth have been made by several investigators. Grieve et al. [1981] analyzed geological and stratigraphic data and Ivanov et al. [1982] and Basilevsky et al. [1983] analyzed melt layer horizons data sets. These data sets were found to be fit by $\Delta Y_{\mathrm{st}} / D_{\mathrm{p}}=0.1$, within the accuracy of the data [Melosh and Ivanov, 1999]. The crater diameter $\left(D_{\mathrm{c}}\right)$ to transient crater diameter at maximum penetration ranges from 2 to 2.5 . 


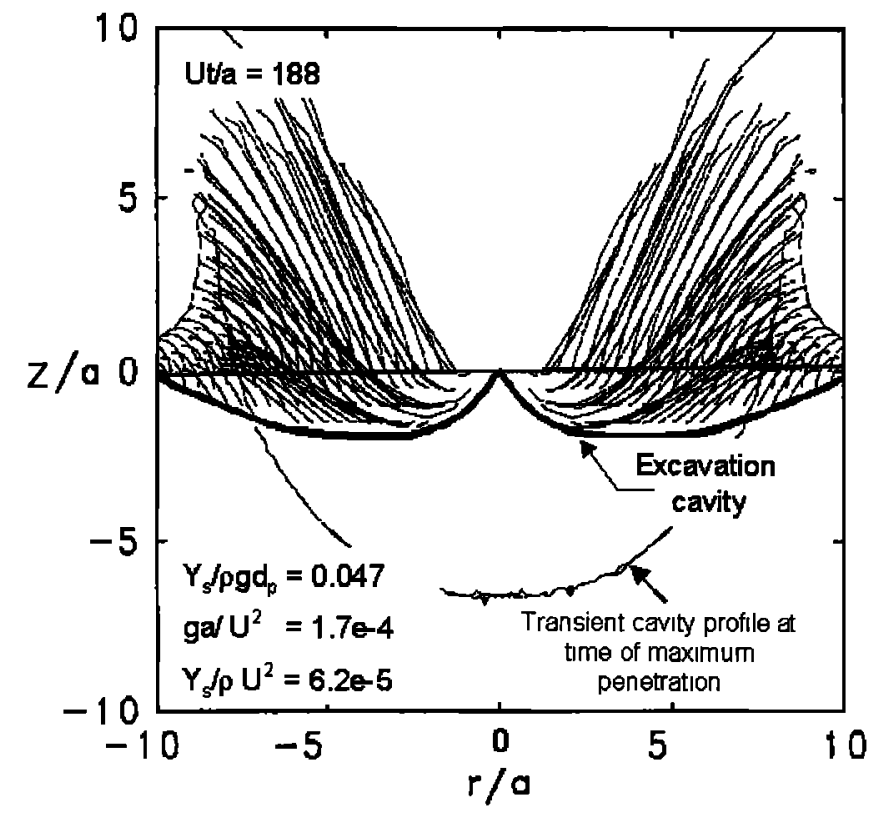

Figure 10. Excavation cavity profile. Tracer particles that are ejected above planet's surface are shown for case plotted in Figure 5. These define extent of excavation cavity. Z/a and $r / a$ are defined in Figure 1 caption.

Replacing $D_{\mathrm{c}}$ by $D_{\mathrm{p}}$ gives $\Delta Y_{\mathrm{s}} / D_{\mathrm{c}}=0.2$ to 0.25 , which is in agreement with the scaling law from the present calculations.

\subsection{Crater Scaling Relationships}

Holsapple and Schmidt [1987] developed a coupling theory approach to crater scaling. They showed that the coupling theory led to power law scaling functions for both the strength and gravity dominated regimes. They fit the gravity scaling parameter $\left(\mathrm{ga} / \mathrm{U}^{2}\right)$ to experimental data that had variations in impactor radius by an order of magitude, impact velocity by 4 orders of magnitude, and gravity by 3 orders of magnitude. O'Keefe and Ahrens [1993] performed a series of numerical calculations that further supported the scaling theory. In addition, they used the code calculations to establish scaling relationships for other crater measures that cannot be readily obtained from experimental data (e.g., depth of penetration and transient crater lip height). One of the objectives of this study is to determine how the features in large complex craters relate to the transient cavity measurements and thus the initial impact conditions, specifically, to establish those scaling relationships.

In the case of large complex craters (gravity driven) the crater geometrical measures (e.g., the maximum depth of penetration and maximum diameter scale as $K(\mathrm{p} / \delta)^{-0.26}\left(\mathrm{ga} / \mathrm{I}^{2}\right)^{-022}$. The gravity exponent $(-0.22)$ in the above expression was determined from laboratory experiments, field data, and numerical code calculations over a wide range of conditions [Holsapple and Schmidt, 1987; O'Keefe and Ahrens, 1993], and the planetary density to impactor density exponent $(-0.26)$ was developed by Holsapple and Schmidt [1982] from normal density impact data and reduced density impact calculations [O'Keefe and Ahrens, 1982].

These fits reasonably agree with the present code calculations over a range of density variations that bounds the expected range for comets and asteroids $\left(0.1\right.$ to $\left.7.8 \mathrm{~g} / \mathrm{cm}^{3}\right)$ [O'Keefe and Ahrens, 1982]. The magnitude of the proportionality constant $K$ depends on the crater measure being considered. We determined the constants $K$ for the maximum depth of penetration, the transient cavity diameter at the time of maximum penetration and the stratigraphy rotation diameter, and from these, we derived the other relationships.

In the gravity dominated regime, the maximum depth of penetration does not depend upon the planet's strength. Figure 7 shows the maximum depth of penetration for strengthless fluids $\left(Y_{\mathrm{S}} / \mathrm{p} g d_{\mathrm{p}}=0.0\right)$ and cases with strength that are gravity dominated $\left(Y_{\mathrm{s}} / \rho g d_{\mathrm{p}}=0.0,0.047,0.095\right.$, and 0.14$)$. Note that while the maximum dimensionless depth of penetration is the same for these cases, the number of centerline oscillations vary. It follows from this plot that the time of maximum penetration for complex craters scales as $t_{\mathrm{mp}}=18 d_{\mathrm{p}} / U$, and that the time for the first peak to collapse to the surface level scales of $Y_{\mathrm{s}} / \rho g d_{\mathrm{p}}$ and is roughly 6 to 8 times longer in duration than the time for maximum penetration.

Several key measures of the crater morphology are given in Figure 11. In Figure 11a we show the maximum transient crater diameters $D_{\mathrm{p}}$ normalized by $d_{\mathrm{p}}$ versus the normalized strength at depth. From the scaling theory of Hosapple and Schmidt [1982], we expect that this ratio should be independent of gravity and the magnitude or model used for strength. This has been shown by our previous calculations using a Von Mises strength model [O'Keefe and Ahrens, 1994] and the present calculations using a geologic strength model and also the calculations by Ivanov and Kostuchenko [1997] using an acoustic fluidization strength model. It is important to note that the ratio of the depth of penetrations to the maximum transient crater diameter is not independent of the material strength and varies significantly with different models. The stratigraphy rotation diameter is defined as where the stratigraphy is asymmetric with respect to the transient crater wall and has rotated by $90^{\circ}$. The number of the centerline interface oscillations above the preimpact surface level is also indicated. Referring to Figure $11 \mathrm{a}$, note that those relative measures are nearly constant for variations in $Y_{\mathrm{s}} / \rho g d_{\mathrm{p}}$ which represents impacts into fluids and the transition in rock from coinplex to simple craters.

We have chosen to normalize many of the scaling laws by the crater diameter at the time of maximum penetration not only because transient crater shape is invariant of material models but also because the observable change in stratigraphy is correlated with the transient crater diameter at the time of maximum penetration.

Figure 11a shows various crater ratios as a function of $Y_{\mathrm{s}} / \rho g d_{\mathrm{p}}$ The proportionality constants $K$ for various scaling laws were determined from the data plotted in Figure 11a are given in Table 2. The fits to the data are for results for the gravity-driven regime. The constants that are the result of the fits to the data are given in scaling laws 1-5 in Table 2, and the magnitudes are shown as best fit lines in Figure 11a. Scaling laws 6 and 7 are the results of manipulating the above equations. Scaling law 6 is the ratio of scaling laws 2 and 1 . Scaling law 7 was obtained by eliminating $D_{\mathrm{p}}$ from scaling laws 2 and 3 and solving for the impactor diameter $(2 a)$. At the time of maximum penetration the ratio of the diameter of the $90^{\circ}$ rotation of the stratigraphy and transient crater diameter is 1.12 . The ratio of the transient crater diameter to the maximum depth of penetration at the time of maximum penetration is the ratio of the above constants and is 1.9 (Table 2, scaling law 6).

The inner ring forms and grows out the central peak. It has a threshold for formation and in contrast to the measures shown in Figure 11a, the inner ring diameter shown in Figure $11 \mathrm{~b}$ varies 

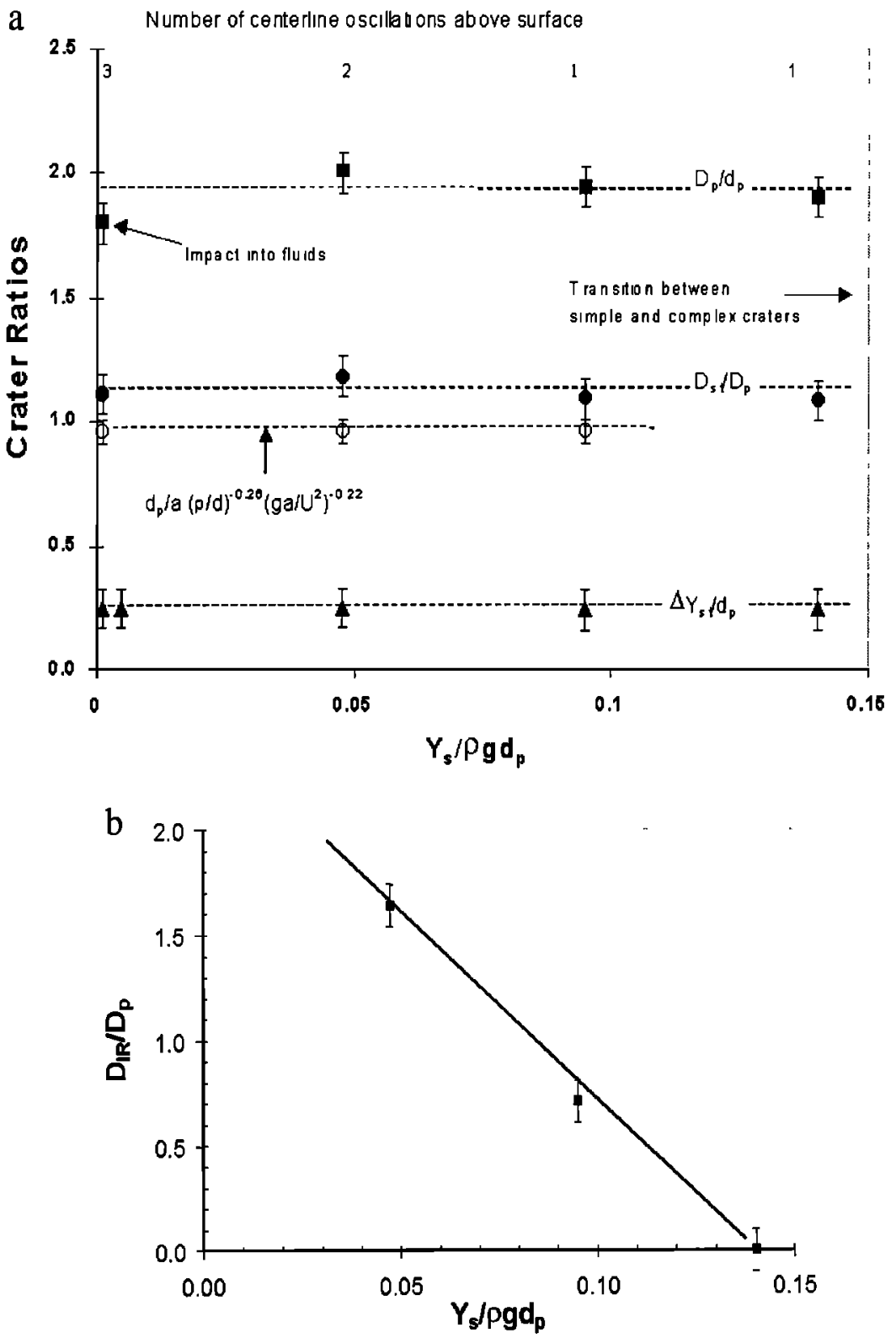

Figure 11. (a) Impact penetration depth, target rotation diameter and central peak uplift . Four quantities are plotted, and the number of centerline interface oscillations above preimpact surface level is given at the top. In addition, quantity defined in Equation (3) is plotted, and the constant $(0.96)$ is obtained from the present plot. Crater diameter at maximum penetration $\left(D_{\mathrm{p}}\right)$ normalized by depth of penetration for zero-strength case $\left(d_{\mathrm{p}}\right)$ is plotted. Dashed lines are average of the given functions. Stratigraphy rotation diameter $D_{\text {st }}$ as defined in text normalized by $d_{\mathrm{p}}$. Stratigraphic uplift, $\Delta \mathrm{Y}_{\mathrm{st}}$, normalized by $d_{\mathrm{p}}$. (b) Inner ring, $\mathrm{D}_{\mathrm{IR}}$, and secondary ring diameters is normalized by the crater diameter at time of maximum penetration versus $Y_{\mathrm{s}} / \rho g d_{\mathrm{p}}$.

inversely with $Y_{\mathrm{s}} / \rho g d_{\mathrm{p}}$. Because the inner ring diameter varies with $Y_{\mathrm{s}} / \rho g d_{\mathrm{p}}$, it does not uniquely constrain the impact parameters.

The stratigraphy rotation diameter $D_{\text {st }}$ can be used to determine the maximum depth of penetration and degree of uplifting and to place a constraint on the initial impact parameters $(a, U, \delta)$. The depth of penetration as a function diameter where the stratigraphy is rotated by $90^{\circ}$ (Table 2 , scaling law 2,) and the impactor diameter as a function of diameter where the stratigraphy is rotated by $90^{\circ}$ (Table 2 , scaling law 7) were calculated, and the results are plotted in Figures 12 and 13.

\section{Conclusions}

We have numerically modeled impacts on planets for a range of planetary gravities and material strengths that correspond to a broad range of impactor parameters. We developed a useful scaling parameter that is a measure of the final crater morphology. Here $Y_{\mathrm{s}} / \rho g d_{\mathrm{p}}$ planetary material strength $\left(Y_{\mathrm{s}}\right)$ is divided by the overburden pressure at the maximum depth of penetration $\left(d_{\mathrm{p}}\right)$ under zero-strength conditions.

This parameter is also a measure of the degree to which a planet can support a feature of a given characteristic height 


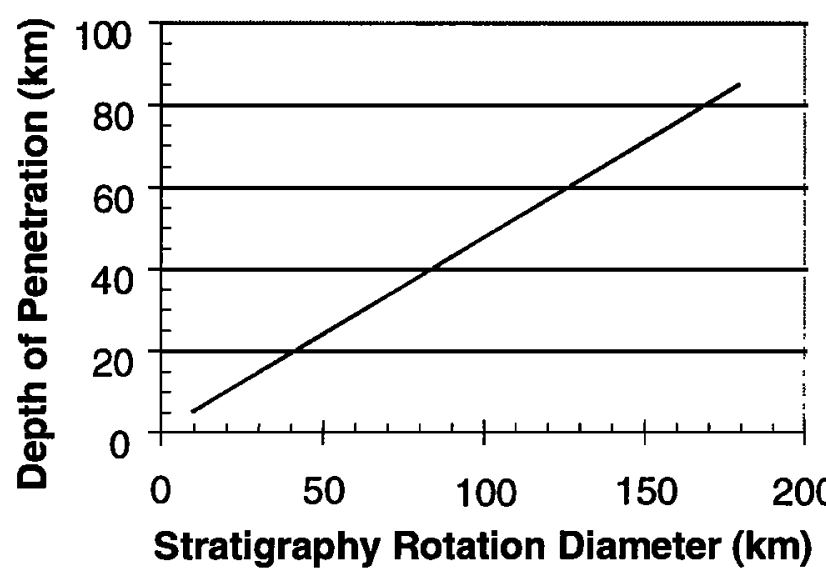

Figure 12. Depth of penetration versus diameter, where initially horizontally oriented rock has been rotated $90^{\circ}$ away from the outward normal to half-space.

relative to the maximum depth of penetration. When $Y_{\mathrm{S}} / \rho g d_{\mathrm{p}}>$ 0.15 , the planetary strength terminates the growth and the development of the crater, and the final crater shape has a simple bowl shape. In contrast, when $Y_{\mathrm{s}} / \rho g d_{\mathrm{p}}<0.15$, the gravitational force terminates the growth of the transient cavity and drives subsequent motions. The transition between simple and complex craters was found to be fairly abrupt. The transition boundary scales as $1 / g$ which has been shown to be the case for the terrestrial planets and satellites [Schenk, 1983].

While we understand that this transition is driven by both the planet's gravity and strength, the understanding of the strength and its accurate modeling is not well understood. In the case of geologic strength model, when we infer the strength at depth, $Y_{\mathrm{s}}$, from the transition diameter from simple to complex craters for the Earth, we get an effective strength at depth in the range of tens of bars as compared to the undamaged magnitude which is in the range of tens of kilobars. The static collapse models have to assume that the effective strength is in the order of bars and that

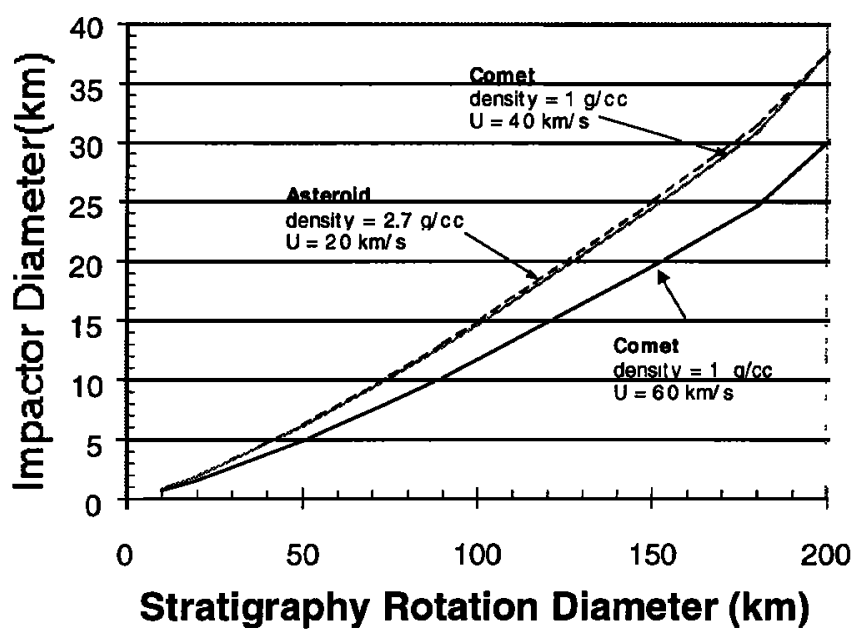

Figure 13. Impactor diameter versus diameter where the stratigraphy is rotated by $90^{\circ}$.

the internal angle of friction is near zero [e.g., Melosh and Ivanov, 1999]. The calculations of O'Keefe and Ahrens [1999] accounting for rock damage found that there was at least an order of magnitude increase in the transition threshold and thus the strength at depth. This puts the strength at depth in the range of a fraction of a kilobar.

In the case of coinplex craters we found that the collapse of the transient cavity results in the development of a tall, transient central peak that oscillates and drives surface waves that are arrested by the balance between the gravitational force and planetary strength. This produces the wide range of multiringed craters that have long been mapped on the Moon. These features occur when $Y_{\mathrm{s}} / \rho g d_{\mathrm{p}}<0.15$. The diameter of the ring increases with decreasing magnitude of $Y_{\mathrm{s}} / \rho g d_{\mathrm{p}}$. In addition, we found that the underlying stratigraphy is inverted outside of the transientcavity diameter, but not inside. On the inside and at and near the centerline, the stratigraphy is mixed. This is consistent with the

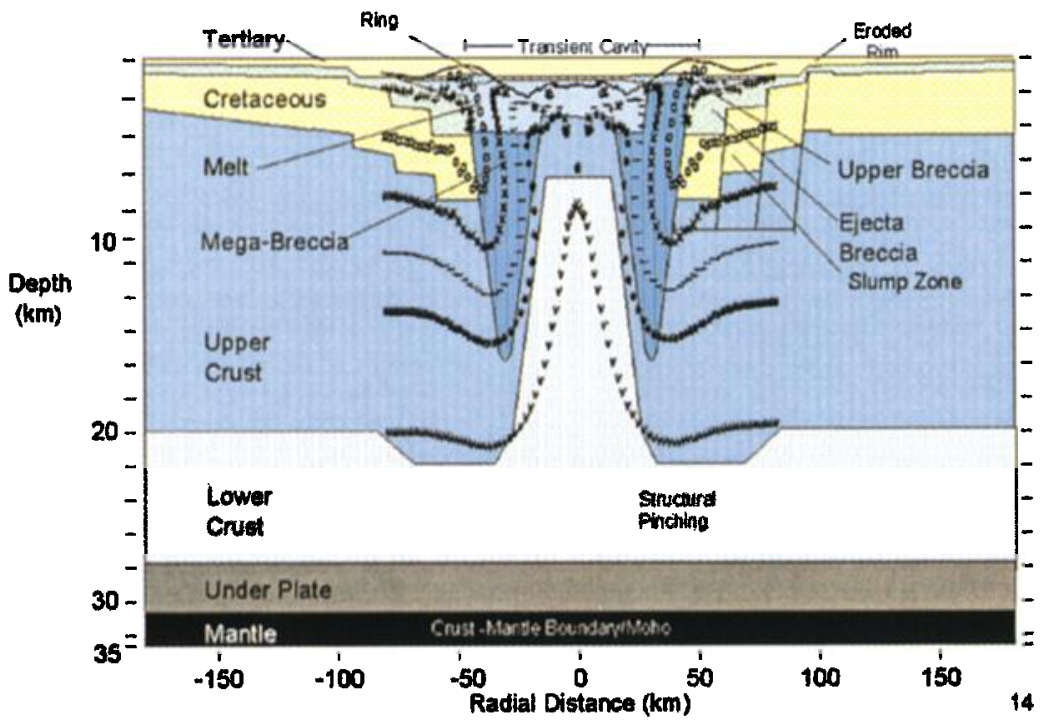

Plate 1. Comparison of the Chicxulub postimpact crater geology with present calculations. Postimpact crater geology is from [Hildebrand et al., 1998] and calculations correspond to $Y_{s} / \rho g d_{\mathrm{p}}=0.047, g a / U^{2}=1.7 \times 10^{-4}, Y_{s}$ $/ \rho U^{2}=5.8 \times 10^{-2}$. Crater shown would result from a $12 \mathrm{~km}$ diameter asteroid impacting at $20 \mathrm{~km} / \mathrm{s}$ or, equivalently, an $11 \mathrm{~km}$ diameter comet impacting at $60 \mathrm{~km} / \mathrm{s}$. 
mixing of melt and rock fragments that is found, for example, in large-scale impacts on the Earth and associated with suevite found at the Ries crater [Pohl et al., 1977]. Moreover, we found that the deformation structure is similar in both simple and complex craters. This change in stratigraphy should be observable using remote sensing, drilling, seismic imaging, and gravity mapping methods.

We have developed scaling laws for the maximum depth of penetration, cavity diameter at maximum penetration, stratigraphy rotation diameter, and impactor diameter as a function of stratigraphy rotation diameter (Table 2). The change in stratigraphy also delineates the edge of the transient cavity. Given the relationship between the stratigraphy rotation diameter and the transient cavity, a plausible range for the impactor parameters, $a, \delta$, and $U$ can be obtained. In contrast with the above crater measures that are not a function of $Y_{s} / \rho g d_{p}$ in the complex crater regime, we found that the inner ring diameter does vary with $Y_{\mathrm{s}} / \rho g d_{\mathrm{p}}$.

The above scaling relations can be used to estimate the parameters of the impactor that produced the Chicxulub (Yucatan, Mexico) crater. This crater has been studied extensively by a number of researchers [e.g., Hildebrand et al., 1998; Morgan et al., 1997; Pilkington et al., 1994; Pope et al., 1996; Sharpton et al., 1993]. The stratigraphy rotation diameter from both seismic and gravity measurements is estimated to be in the range of 90 to $105 \mathrm{~km}$ [Hildebrand et al., 1998]. Referring to Figure 12, for a stratigraphic rotation diameter of $90 \mathrm{~km}$ the maximum depth of penetration is $43 \mathrm{~km}$. The impactor diameter can be estimated from Figure 13. For an asteroid impact at 20 $\mathrm{km} / \mathrm{s}$, or a comet impact at $40 \mathrm{~km} / \mathrm{s}$, the asteroid diameter would be $\sim 13 \mathrm{~km}$. For a comet at $60 \mathrm{~km} / \mathrm{s}$, the diameter would be $\sim 10$ km.

The postimpact stratigraphy for the Chicxulub crater was determined by integrating seismic and gravity measurements and data from drill hole samples and is shown in Plate 1. The data are compared to the final crater stratigraphy for the complex crater calculations shown in Figure 5. While we did not attempt to model the detailed stratigraphy of the Chicxulub area (e.g., the water layer), the features of our calculation correlate well with the model developed from the field data. Our calculations exhibit more of the features than other efforts that attempted to match the initial Chicxulub strata [Ivanov et al., 1996]. Referring to Figure 2 and starting at the right edge of the crater, the calculations show the downward displacement of material near and below the surface. This corresponds to the region that has been described as the "slump zone." At depth and near the region of the central uplift, the dipping of the stratigraphy near the central uplift region is also described by the calculations. This zone is called the "pinched zone." The region just outside the central uplift region has stratigraphy that is rotated by $90^{\circ}$ and yields a stratigraphy rotation crater diameter similar to our results. Our calculations show that immediately beneath the transient crater the rock has undergone large displacements and shear deformations. The rock in this region is expected to be brecciated. This corresponds to the "megabreccia" zone in the field data. Finally, moving to the centerline, the large central uplift shown in the calculation also correlates with the field data.

Acknowledgments. Research was supported by NASA. We appreciate the computational assistance of $M$. E. Lainhart and thank Elizabeth Turtle (University of Arizona) and Sarah Stewart-Mukhopadhyay for their careful and insightful reviews.
Contribution 8542, Division of Geological and Planetary Sciences, California Institute of Technology.

\section{References}

Baldwin, R. B., The Face of the Moon, Univ. Chicago Press, Chicago, Ill., 1949.

Basilevsky, A. T., B. A. Ivanov, K. P. Florensky, O. I. Yakolev, V. I. Fel'dman et al. Impact Craters on the Moon and Other Planets. Nauka, Moscow: 1983. (Engl. tech. transl. NASA Tech. Morrow. TM 77667 1985. )

Bratt, S. R., S. Solomon, and J. W. Head, The evolution of impact basins: Cooling, subsidence, and thermal stress, J.Geophys. Res., 90, 12415-12433, 1985.

Cristescu, N., Dynamic Plasticity, pp. 509-558, John Wiley, New York, 1967.

Grieve, R. A. F., P. B. Robertson and M. R. Dence, Constraints on the formation of ring impact structures, in Multi-ring Basins, edited by P. Schultz and R. B. Merrill, pp. 37-57, Pergamon Press, New York, Oxford, Toronto, Sydney, Frankfurt, 1981.

Hildebrand, A. R., M. Pilkington, C. Ortiz-Aleman, R. Chavez, J. Urrutia-Fucugauchi, M. Connors, E. Graniel-Castro, A. CamaraZi, J. Halpenny, and D. Niehaus, Mapping Chicxulub crater structure with gravity and seismic reflection data, in Meteorites: Flux With Time and Impact Effects, edited by M. M. Grady et al.,, Geol. Soc. Spec. Publ., 140, 177-193, 1998.

Holsapple, K. A., and R. M. Schmidt, On the scaling of crater dimensions, 2, Impact processes, J. Geophys. Res., 87, 1849-1870, 1982.

Holsapple, K. A., and R. M. Schmidt, Point-source solutions and coupling parameters in cratering mechanics, J. Geophys. Res., 92, 6350-6376, 1987.

Ivanov, B. A., A. T. Basilevsky and L. V. Sazonoya, Formation of the central uplift in meteoritic craters, Meteoritika, 40, pp. 60-81, 1982. (Engl. tech. transl. 1986, NASA TM-88427)

Ivanov, B. A., D. D. Badukov, O. I. Yakovlev, M. V. Gerasimov, Y. P. Dikov, K. O. Pope, and A. C. Ocampo, Degassing of sedimentary rocks due to Chicxulub impact: Hydrocode and physical simulations, in The Cretaceous Tertiary Event and Other Catastrophes in Earth History, edited by G. Ryder, et al., Spec. Pap. Geol. Soc. Amer., 30, 125-142, 1996.

Ivanov, B. A., V. N. Kostuchenko, Block oscillation model for impact crater collapse (abstract), in Lunar Planet. Sci, Conf. 28th CD ROM, 1997.

Jaeger, J. C., and N. G. W. Cook, Fundamentals of Rock Mechanics, 593 pp., Chapman and Hall, New York, 1979.

Leith, A. C., and W. B. McKinnon, Terrace width variations in complex Mercurian craters and the transient strength of cratered Mercurian and lunar crust, J. Geophys. Res., 96, 20923-20931, 1991.

McGlaun, J. M., Thomson, S. L., CTH: A Three-dimensional shock wave physics code, Int. J. Impact Eng., 10, 360-361, 1990.

Melosh, H. J., Acoustic fluidization. Am. Sci., 71, pp. 158-165, 1983

Melosh, H. J., Impact Cratering, A Geologic Process, 245 pp., Oxford Univ. Press, New York, 1989.

Melosh, H. J. and B. A. Ivanov, Impact crater collapse, Annv. Rev. Earth Planet. Sci., pp. 385-415, 1999

Morgan, J. et al., Size and morphology and the Chicxulub impact crater, Nature, 390, 472-476, 1997.

Murray, J. B., Oscillating peak model of basin and crater formation, Moon Planets, 22, 269-291, 1980.

O'Keefe, J. D., and T. J. Ahrens, Cometary and meteorite swarm impact on planetary surfaces, J. Geophys. Res., 87, 6668-6680, 1982.

O'Keefe, J. D., and T. J. Ahrens, Planetary cratering mechanics, J. Geophys. Res., 98, 17011-17028, 1993.

O'Keefe, J. D., and T. J. Ahrens, Planetary strength, central peak oscillation, and formation of complex craters (abstract), Lunar Planet. Sci., 27th, 983-984, 1996.

O'Keefe, J. D., and T. J. Ahrens, Calculations of complex crater formation extended to thermo-elastic regime (abstract), Lunar Planet. Sci. Conf., 29th, 1998.

O'Keefe, J. D., and T. J. Ahrens, Deep seated faulting in the formation of complex craters, abstr. 1304, Lunar Planet. Sci. Conf., 30th, 1999 
Pilkington, M., A. R. Hildebrand, and C. Ortiz-Aleman, Gravity and magnetic-field modeling and structure of the Chicxulub Crater, Mexico, J. Geophys. Res., 99, 13147-13162, 1994.

Pohl, J., D. Stöffler, H. Gall, and K. Ernstson, The Ries impact crater, in Impact and Explosion Cratering, edited by D. J. Roddy et al., pp. 343-404, Pergamon, Tarrytown, N. Y., 1977.

Pope, K. O., A. C. Ocampo, G. L. Kinsland, and R. Smith, Surface expression of the Chicxulub crater, Geology, 24, 527-530, 1996.

Sharpton, V. L., K. Burke, A. Camargo-Zanoguera, S. A. Hall, D. S. Lee, L. E. Marin, G. Suárez-Reynoso, J. M. Quezada-Muñeton, P. D. Spudis, and J. Urrutia-Fucugauchi, Chicxulub multi-ring impact basin-size and other characteristics derived from gravity analysis, Science, 261, 1564-1567, 1993.

Schenk, P. M., Crater formatoin and modification on the icy satellites of Uranus and Saturn: depth/diameter and central peak occurence, J. Geophys. Res., 94, 3813-3832, 1989

Van Dorn, W. G., Tsunamis on the Moon?, Nature, 220, 1102-1107, 1968.

T. J. Ahrens and J. D. O'Keefe, Lindhurst Laboratory of Experimental Geophysics, Seismological Laboratory, 252-21, California Institute of Technology Pasadena, CA 91125 . tja@caltech.edu 